\title{
Factors Affecting Sleep Problems in Preschoolers
}

\author{
Eka Wahyuningrum $^{1}$, Natalia Ratna Yulianti ${ }^{1}$, Andri Kenti Gayatina ${ }^{1}$ \\ ${ }^{1}$ Sekolah Tinggi Ilmu Kesehatan St. Elisabeth Semarang, Central Java, Indonesia \\ Corresponding Author: Eka Wahyuningrum (Ekawahyu877@gmail.com)
}

\begin{abstract}
Background: Sleep problems are self-care deficits of sleep experienced by more than $44 \%$ of preschoolers. Some studies have showed that physical, psychological, family, environmental, and temperamental factors could cause sleep problems among children. However, other research showed that there is no correlation between sleep problems and environmental factors. There are pro-cons regarding the causes of sleep problems.

Purpose: The purpose of this study was to analyze factors affecting sleep problems among preschoolers.

Methods: A cross-sectional study was conducted among 297 preschoolers selected by systematic random sampling. Data were collected using the Children's Sleep Habits Questionnaires (CSHQ) and analyzed using bivariate (Chi-Square and Fisher tests) and multivariate (logistic regression) analyses.

Results: Results of the bivariate analysis showed that some variables were related to sleep problems among preschoolers, including family income $(p=0.027)$, the education level of the mother $(p<0.001)$, and bed-sharing $(p=0.003)$. Multivariate analysis found that factors related to sleep problems were bed-sharing $(p=0.031 ; \mathrm{OR}=2.377)$, gadget use in two hours before sleep $(p=0.039 ; \mathrm{OR}=2.703)$, and the education level of the mother $(p=0.007$; $\mathrm{OR}=2.244$ ).

Conclusion: Factors related to sleep problems in preschoolers were bed-sharing, gadget use in two hours before sleep, the education level of the mother, and family income. This study recommends that environmental and family factors should be modified by limiting bed-sharing and reducing the use of gadgets before bedtime.
\end{abstract}

Keywords: Bed-sharing; gadget use; preschooler; sleep problem

How to cite: Wahyuningrum, E., Yulianti, N. R., \& Gayatina, A. K. (2020). Factors affecting sleep problems in preschoolers. Nurse Media Journal of Nursing, 10(2), 107118. doi:10.14710/nmjn.v10i2.26649

Permalink/DOI: https://doi.org/10.14710/nmjn.v10i2.26649

\section{BACKGROUND}

Sleep problems are forms of self-care deficits of sleep or unhealthy children's sleep habits that are characterized by a score of more than 41 in the Children's Sleep Habits Questionnaire (CSHQ) (Owens, Spirito, \& McGuinn, 2000). Sleep problems reported in CSHQ include bedtime resistance, sleep onset delay, sleep duration, sleep anxiety, night wakening, sleep-disordered breathing, daytime sleepiness, and parasomnias (Owens et 
al., 2000). Sleep problems may hinder children to achieve optimal health. As children's growth hormone reaches its peak levels during deep sleep at night, sleep plays an important role in brain development, recovery, metabolic balance, and has a significant influence on health and development over a long period of time in life. Healthy sleep directly supports neurocognition by increasing synapse changes, neurotransmitter activation, and neuronal firing that facilitate the ability of memory consolidation, modulation, learning arrangements, and visual processes (Astill, Heidjen, Ijzendoorn, \& Someren, 2012; Tso et al., 2016).

Some studies have showed more than $44 \%$ of preschoolers experienced sleep problems (Amintehran et al., 2013; Wahyuningrum, Rahmat, \& Hartini, 2018). Research in Iran found that $64,9 \%$ of preschoolers experienced sleep problems such as excessive daytime sleepiness (Amintehran et al., 2013). In Indonesia, especially in Semarang city, a study reported a mean score of $>41$ in the CSHQ among preschoolers involved in the study, indicating problems of sleep (Wahyuningrum et al., 2018). Unresolved sleep problems result in physical, cognitive, psychological, and social problems. The examples of these problems include suboptimal growth, obesity, lack of school readiness, poor behavior, and lack of cognitive competence (Biggs et al., 2015; Speirs et al., 2014; Tso et al., 2016; Zahara, Hartanto, \& Adyaksa, 2013).

Sleep problems in children are evident to be affected by physical, psychological, family, environmental, and temperamental factors (Kliegman, Stanton, \& St Geme, 2016). Regarding the family factor, a study reported that the quality of both mother-infant and father-infant interactions was positively related to children's percentage of night-time sleep at preschool age (Bordeleau, Bernier, \& Carrier, 2012). In terms of environmental factor, media exposure may lead to sleep difficulties through negative impacts on sleep scheduled and routines (Bathory \& Tomopoulos, 2017). In addition, culture also affects sleep problem on preschooler as reported in a study about cultural differences between Asian predominant and Caucasian predominant (Mindell, Sadeh, Kwon, \& Goh, 2013). In Indonesia, $72.6 \%$ of children have some habits that could lead to sleep problems such as bed-sharing, late bedtime, and short nighttime sleep (Mileva-Seitz, BakermansKranenburg, Battaini, \& Luijk, 2017; Mindell et al., 2013).

Factors affecting sleep problems vary in different studies. In Tehran, research focusing on analyzing the correlation between ages and sleep problems found some differences in the mean score of sleep duration between the pre-school age and school-age groups (Amintehran et al., 2013). Furthermore, Mindell et al. (2013) found significant crosscultural differences in sleep pattern, sleeping arrangement, and parent-reported sleep problems in preschool-aged children. This study however did not analyze other factors like socioeconomic and environmental factors that might affect sleep. In Indonesia, while a study stated that sleep problems could affect the growth of children (Zahara et al., 2013), research investigating factors affecting sleep problems among preschoolers is rarely found. Furthermore, though some studies reported that physical, psychological, family, environmental, and temperamental factors affect sleep problems in preschoolers, other research showed no correlation between sleep problems and environmental factors such as the availability of television, computers, cell phones, and video games in the bedroom 
(Amalina, Sitaresmi, \& Gamayanti, 2015). Thus, it is important to conduct a study to identify factors that are related to sleep problems among preschoolers.

\section{PURPOSE}

This study aimed to analyze factors affecting sleep problems among preschoolers.

\section{METHODS}

\section{Design and samples}

This study used a cross-sectional research design and was conducted in a sub-district in Semarang City, Indonesia. Forty-eight kindergartens are registered in the district, and 16 kindergartens were selected using systematic random sampling for research purposes. The number of the sample was determined by using the "rule of the thumb" (Dharma, 2011); therefore, the minimal number of samples was 60-300. The inclusion criteria were children aged 4-6 years old, being kindergarten pupils in the research area, and expressed willingness to participate in the study as shown by their primary caregivers. The exclusion criteria were children with autism and with incomplete questionnaire. In the research process, two kindergartens were dropped out as they did not have sufficient number of students. Thus, only 14 Kindergartens were included in this study with a total of 297 respondents who met the inclusion and exclusion criteria.

\section{Research instrument and data collection}

Data of sleep problems were collected using the Children's Sleep Habits Questionnaire (CSHQ). The Indonesian version of this questionnaire was validated by Hartini, Sunartini, Herini, and Takada (2017). The internal consistency of all items of the CHSQ was 0.80. The CSHQ is suitable for screening sleep behavior problems in Indonesian children aged 4-10 years old. The CSHQ consists of 33 statements and contains 8 sleep problem domains (bedtime resistance, sleep onset delay, sleep duration, sleep anxiety, night waking, parasomnia, sleep-disordered breathing, and daytime sleepiness). Data on physical, family and environmental factors were collected using a questionnaire that was completed by primary caregivers. The questionnaire required information about the age of the child, gender, history of illness, family income, working mother status, parental status, education level of mother, bedroom, bed (bed-sharing), TV in the bedroom, electronic devices in the bedroom, and gadget use in two hours before sleep. The data were collected from June to August 2019. Primary caregivers completed the CSHQ and questionnaires about physical, family, and environmental factors.

\section{Data analysis}

The collected data were analyzed using a univariate analysis to determine the frequency distribution and bivariate analysis using the Chi-square and Fisher tests to determine factors related to sleep problems among preschoolers. A multivariate analysis using the logistic regression was then performed by including independent variables that had a $\mathrm{p}$ value of $<0.25$. Multivariate analyses were used to analyze variables simultaneously and get the best and simplest model that described the relationship between the independent and dependent variables. Any variables having a significant bivariate test at some arbitrary levels was selected as a candidate for the multivariate analysis. If researchers used a traditional level, such us 0.05 , for selected candidate variables in a multivariate test, there could be failure in identifying variables known to be important. The researchers 
based this on the Wald test from logistic regression and p-value cut-off point of 0.25 . The dominant factor could be known by the Odds Ratio value that was shown in the logistic regression test results.

\section{Ethical consideration}

This study obtained ethical approval from the Research Ethics Committee of Faculty of Medicine, Universitas Diponegoro (Number 293/EC/KEPK/FKUNDIP/VII/2019). The permission from the Educational Authorities in Semarang city was secured prior to the study, as well as informed consent from the parents of all respondents.

\section{RESULTS}

\section{Characteristics of respondents}

As presented in Table 1, the results showed that sleep problems were experienced by a majority of respondents in this study (87.5\%). Most of them were boys $(52.2 \%)$, aged $\geq 5$ years old $(50.8 \%)$, and did not have a history of illness $(92.3 \%)$. Furthermore, most respondents had parents with family income of less than five million rupiahs per month (67.3\%), unemployed mothers $(51.2 \%)$, complete parents $(92.3 \%)$, and graduated from elementary, middle, or high school (75.8\%). Furthermore, a majority of children slept in the same room with their parents $(89.9 \%)$, shared a bed with parents $(80.1 \%)$, and had electronic devices in their room $(68 \%)$.

Table 1. The characteristic of respondents $(n=297)$

\begin{tabular}{|c|c|c|}
\hline Characteristics of respondents & $f$ & $\%$ \\
\hline \multicolumn{3}{|l|}{ Sleep on preschooler } \\
\hline Sleep problems $(\mathrm{CSHQ}>41)$ & 260 & 87.5 \\
\hline Normal sleep habits $(\mathrm{CSHQ} \leq 41)$ & 37 & 12.5 \\
\hline \multicolumn{3}{|l|}{ Physical factors (age) } \\
\hline$<5$ years & 146 & 49.2 \\
\hline$\geq 5$ years & 151 & 50.8 \\
\hline \multicolumn{3}{|l|}{ Physical factors (gender) } \\
\hline Boys & 156 & 52.5 \\
\hline Girls & 141 & 47.5 \\
\hline \multicolumn{3}{|l|}{ Physical factors (history of illness) } \\
\hline No & 274 & 92.3 \\
\hline Yes & 23 & 7.7 \\
\hline \multicolumn{3}{|l|}{ Family factors (family income) } \\
\hline$\geq$ Rp. $5.000 .000,00$ per month & 97 & 32.7 \\
\hline < Rp. 5.000.000,00 per month & 200 & 67.3 \\
\hline \multicolumn{3}{|l|}{ Family factors (working status of the mother) } \\
\hline Unemployed mothers & 152 & 51.2 \\
\hline Working mother & 145 & 48.8 \\
\hline \multicolumn{3}{|l|}{ Family factors (parental status) } \\
\hline Single parents & 23 & 7.7 \\
\hline Complete parents & 274 & 92.3 \\
\hline \multicolumn{3}{|l|}{ Family factors (education level of mother) } \\
\hline College graduate & 72 & 24.2 \\
\hline Elementary/middle/high school & 225 & 75.8 \\
\hline
\end{tabular}




\begin{tabular}{lrc}
\hline \multicolumn{1}{c}{ Characteristics of respondents } & $f$ & $\%$ \\
\hline Environment factors (bedroom) & 30 & 10.1 \\
$\quad$ Alone & 267 & 89.9 \\
$\quad$ One room with parents & 59 & 19.9 \\
Environment factors (bed-sharing) & 238 & 80.1 \\
$\quad$ Alone & 161 & 54.2 \\
$\quad$ Share with parents & 136 & 45.8 \\
Environment factors (TV in bedroom) & & \\
$\quad$ No & 95 & 32 \\
$\quad$ Yes & 202 & 68 \\
Environment factors (electronic devices in the room) & & \\
$\quad$ No & 211 & 71 \\
$\quad$ Yes & 86 & 29 \\
Gadget use in 2 hours before sleep & & \\
$\quad$ No & & \\
$\quad$ Yes &
\end{tabular}

The correlation between physical, family, environmental factors and sleep problem in preschoolers

Table 2 shows that factors associated with sleep problems among preschoolers were family income $(p=0.027)$, education level of the mother $(p<0.001)$, and bed-sharing $(p=0.003)$. These results indicated that there was a significant relationship between each of these variables with sleep problems.

Table 2. Correlation between physical, family, and environmental factors, and sleep problems among preschoolers $(n=297)$

\begin{tabular}{|c|c|c|c|c|c|}
\hline \multirow{3}{*}{ Variable } & \multicolumn{4}{|c|}{ Children's Sleep Habit } & \multirow{3}{*}{$\begin{array}{c}p- \\
\text { value }\end{array}$} \\
\hline & \multicolumn{2}{|c|}{$\begin{array}{c}\text { CSHQ } \leq 41 \\
\text { (Normal sleep) }\end{array}$} & \multicolumn{2}{|c|}{$\begin{array}{c}\text { CSHQ >41 } \\
\text { (Sleep problem) }\end{array}$} & \\
\hline & $n$ & $\%$ & $n$ & $\%$ & \\
\hline \multicolumn{6}{|l|}{ Age } \\
\hline$<5$ years $* *$ & 15 & 10.3 & 131 & 89.7 & $0.262^{\mathrm{a}}$ \\
\hline$\geq 5$ year & 22 & 14.6 & 129 & 85.4 & \\
\hline \multicolumn{6}{|l|}{ Gender } \\
\hline Boys** & 16 & 10.3 & 140 & 89.7 & $0.227^{\mathrm{a}}$ \\
\hline Girls & 21 & 14.9 & 120 & 85.1 & \\
\hline \multicolumn{6}{|l|}{ History of illness } \\
\hline No** & 34 & 12.4 & 240 & 87.6 & $1.000^{\mathrm{b}}$ \\
\hline Yes & 3 & 13 & 20 & 87 & \\
\hline \multicolumn{6}{|l|}{ Family income } \\
\hline$\geq$ Rp. $5.000 .000,00$ per month $* *$ & 18 & 18.6 & 79 & 81.4 & $0.027^{\mathrm{a}^{*}}$ \\
\hline$<$ Rp. 5.000.000,00 per month & 19 & 9.5 & 181 & 90.5 & \\
\hline \multicolumn{6}{|l|}{ Working status of the mother } \\
\hline Unemployed mothers** & 18 & 11.8 & 134 & 88.2 & $0.742^{\mathrm{a}}$ \\
\hline Working mother & 19 & 13.1 & 126 & 86.9 & \\
\hline \multicolumn{6}{|l|}{ Parental status } \\
\hline Single parents & 2 & 8.7 & 21 & 91.3 & $0.751^{\mathrm{b}}$ \\
\hline Complete parents $* *$ & 35 & 12.8 & 239 & 87.2 & \\
\hline
\end{tabular}




\begin{tabular}{|c|c|c|c|c|c|}
\hline \multirow{3}{*}{ Variable } & \multicolumn{4}{|c|}{ Children's Sleep Habit } & \multirow{3}{*}{$\begin{array}{c}p- \\
\text { value }\end{array}$} \\
\hline & \multicolumn{2}{|c|}{$\begin{array}{c}\text { CSHQ } \leq 41 \\
\text { (Normal sleep) }\end{array}$} & \multicolumn{2}{|c|}{$\begin{array}{c}\text { CSHQ >41 } \\
\text { (Sleep problem) }\end{array}$} & \\
\hline & $n$ & $\%$ & $n$ & $\%$ & \\
\hline $\begin{array}{l}\text { Education level of the mother } \\
\text { College graduate** }\end{array}$ & 18 & 25.0 & 54 & 75.0 & $<0.001^{\mathrm{a}^{\mathrm{a}}}$ \\
\hline Elementary/Middle/High School & 19 & 8.4 & 206 & 91.6 & \\
\hline Bedroom & & & & & \\
\hline Alone** & 7 & 23.3 & 23 & 76.7 & $0.076^{\mathrm{b}}$ \\
\hline One room with parents & 30 & 11.2 & 237 & 88.8 & \\
\hline Bed-sharing & & & & & \\
\hline Alone** & 14 & 23.7 & 45 & 76.3 & $0.003^{\mathrm{a}^{*}}$ \\
\hline Share with parents & 23 & 9.7 & 215 & 90.3 & \\
\hline TV in bedroom & & & & & \\
\hline No** & 19 & 11.8 & 142 & 88.2 & $0.709^{\mathrm{b}}$ \\
\hline Yes & 18 & 13.2 & 118 & 86.8 & \\
\hline Electronic devices in the room & & & & & \\
\hline No $* *$ & 15 & 15.8 & 80 & 84.2 & $0.233^{\mathrm{a}}$ \\
\hline Yes & 22 & 10.9 & 180 & 89.1 & \\
\hline Gadget use in 2 hours before sleep & & & & & \\
\hline No** & 31 & 14.7 & 180 & 85.3 & $0.068^{\mathrm{a}}$ \\
\hline Yes & 6 & 7.0 & 80 & 93.0 & \\
\hline
\end{tabular}

\section{The factors influencing sleep problems on preschoolers}

Table 3 shows that the strength of the relationship from the strongest to the weakest is gadget use ( $\mathrm{OR}=2.703)$, bed-sharing $(\mathrm{OR}=2.377)$, and mother's education $(\mathrm{OR}=2.244)$. The dominant factor influencing sleep problems was gadget use $(\mathrm{OR}=2.703)$.

Table 3. Results of multivariate analysis (logistic regression)

\begin{tabular}{llccr}
\hline \multicolumn{1}{c}{ Variable } & Coefficient & $P$ & OR (CI 95\%) \\
\hline Step 1 & Gender & 0.396 & 0.294 & $1.486(0.71-3.11)$ \\
& Family income & -0.181 & 0.676 & $0.835(0.36-1.95)$ \\
& Bedroom & -0.517 & 0.361 & $0.596(0.20-1.81)$ \\
& Bed-sharing & -0.682 & 0.136 & $0.506(0.21-1.24)$ \\
& Gadget use in 2 hours before sleep & -1.085 & 0.030 & $0.338(0.13-0.90)$ \\
& Education level of mother & -1.132 & 0.009 & $0.322(0.14-0.76)$ \\
& Electronic devices in room & -0.424 & 0.270 & $0.654(0.31-1.39)$ \\
Step 2 & 3.452 & $<0.001$ & 31.575 \\
& Constanta & 0.385 & 0.307 & $1.469(0.70-3.07)$ \\
& Gender & -0.499 & 0.377 & $0.607(0.20-1.84)$ \\
& Bedroom & -0.710 & 0.117 & $0.491(0.20-1.19)$ \\
& Bed-sharing & -1.089 & 0.030 & $0.337(0.13-0.90)$ \\
& Gadget use in 2 hours before sleep & -1.217 & 0.002 & $0.296(0.14-0,63)$ \\
& Education level of mother & -0.436 & 0.256 & $0.647(0.30-1.37)$ \\
& Electronic devices in room & 3.429 & $<0.001$ & 30.855 \\
& Constanta & 0.391 & 0.298 & $1.478(0.71-3.09)$ \\
& Gender & -0.881 & 0.029 & $0.414(0.19-0.91)$ \\
& Bed-sharing & -1.050 & 0.034 & $0.350(0.13-0.92)$ \\
\hline
\end{tabular}




\begin{tabular}{llccc}
\hline \multicolumn{1}{c}{ Variable } & Coefficient & $P$ & OR (CI 95\%) \\
\hline \multirow{5}{*}{ Step 4 } & -1.190 & 0.002 & $0.304(0.14-0.64)$ \\
& Education level of mother & -0.416 & 0.276 & $0.660(0.31-1.40)$ \\
& Electronic devices in room & 3.355 & $<0.001$ & 28.657 \\
& Constanta & -0.904 & 0.024 & $0.405(0.18-0.89)$ \\
& Bed-sharing & -0.988 & 0.043 & $0.372(0.14-0.97)$ \\
& Gadget use in 2 hours before sleep & -1.211 & 0.002 & $0.298(0.14-0.63)$ \\
& Education level of mother & -0.439 & 0.248 & $0.645(0.31-1.36)$ \\
Step 5 & Electronic devices in room & 3.519 & $<0.001$ & 33.737 \\
& Constanta & -0.907 & 0.031 & $2.377(1.08-5.22)$ \\
& Bed-sharing & -1.018 & 0.039 & $2.703(1.05-6.96)$ \\
& Gadget use in 2 hours before sleep & -1.185 & 0.007 & $2.244(1.25-4.04)$ \\
& Education level of mother & 3.377 & $<0.001$ & 29.290 \\
\hline
\end{tabular}

\section{DISCUSSION}

This study investigated factors affecting sleep problems in preschoolers. Bed-sharing, gadget use in two-hours before sleep, and education level of mother were factors that affected sleep problems in a majority of preschoolers in this study. In addition, family income is related to sleep problems in children at this age. The results of this study confirm previous research by Amintehran et al (2013), which reported that most preschoolers experienced sleep problems and bedtime resistance, and Wahyuningrum et al. (2018) which found that the mean of sleep habits of preschoolers in the CSHQ was more than 41, indicating most of preschoolers suffered sleep problem. However, sleep problems were found more in younger children, as they experienced a period of transition and adaptation when entering the first year of kindergarten, and thus it could become stressors for children. A child's psychological state is related to sleep problems in children (Bagley, Kelly, Buckhalt, \& El-sheikh, 2016). Most sleep problems on preschoolers in this study were affected by physical, family, and environmental factors.

\section{Bed-sharing}

This study showed that factor affecting sleep problems on preschoolers is bed-sharing. Children who shared a bed with parents had a greater risk of 2.377 experiencing sleep problems than children who slept in their own beds. This study is in line with a study by Lo (2016), which conveyed that one of the main predictors of the lack of quality and quantity of sleep was bed-sharing. A study in Korea also showed that in families with low economic status, bed-sharing habits were associated with poor sleep quality (Chung et al., 2014).

In most Asian cultures, bed-sharing and room-sharing are common. It is the same case in Indonesia, where children usually sleep with their parents. Children share beds in Indonesia as they think that it brings a sense of comfort, safety, and security. This habit starts at birth and continues throughout life (Hollan, 2013; Mindell et al., 2013). However, friends of bed-sharing, both parents and relatives (co-sleepers) may do more activities before going to sleep such as talking and playing which can then cause sleepless nights and sleep disturbance for the preschoolers. Another thing might be that parents are more aware of a child's sleep disorder, as the duration of late sleep results in a child's sleep duration decreasing and parents who are experiencing problems or stress can also interfere with the child's sleep (Wang et al., 2013). Unhealthy sleep or poor sleep hygiene 
from co-sleepers can also result in self-care sleep deficits in their children (Li et al., 2010). The 30-minute habits before bedtime can provide cognitive, psychological, and emotional stimulation. This can delay sleep so that disruption in sleep patterns and circadian rhythm can occur (Maanen et al., 2015).

Sleep and waking are regulated by the circadian process and by a homeostatic process. The circadian process is driven by the circadian clock located in the suprachiasmatic nucleus in the ventral hypothalamus and this clock is synchronized by daily exogenous environmental cues. Some examples of exogenous environmental cues are daily routines (such as hearing alarm clock and eating meals) and zeitgebers (the most powerful zeitgeber is light that activates photoreceptors in the retina inhibiting pineal gland secretion of the sleep-promoting hormone, melatonin) (Bathory \& Tomopoulos, 2017). Friends of bed-sharing could provide preschoolers exogenous environmental cues when they are sleeping (Chung et al., 2014).

\section{Gadget use in two hours before sleep}

In this study, the gadget usage before going to sleep in the bivariate analysis was not related to sleep problems. In the multivariate analysis, however, the gadget usage has a significant relationship to sleep problems. In addition, gadget usage has a greater relationship than mother's education. This result is in accordance with a previous study reporting that there was a significant relationship between the use of touch screen gadget with nighttime sleep, daytime sleep and sleep onset (Cheung, Bedford, Saez De Urabain, Karmiloff-Smith, \& Smith, 2017). Another study has also shown that the habit of using a gadget 30 minutes before bedtime was associated with sleep disorders (Amalina et al., 2015)

Several hypotheses explain why gadget use in two hours before sleep affected sleep problems. First, one of the most zeitgeber (daily exogenous environmental cues) is light, where light exposure from gadget before sleep may alter the sleep/wake cycle through changing melatonin levels (Bathory \& Tomopoulos, 2017). Akacem, Wright, and LeBourgeois (2018) found that robust melatonin suppression remained attenuated for 50 minutes after termination of the light stimulus in response to the bright light stimulus. Melatonin levels did not return to $50 \%$ of preschoolers who observed in the dim light condition 50 minutes after the light exposure. Second, inappropriate content of gadgets can be an emotional stimulus for preschoolers (Garrison, Liekweg, \& Christakis, 2011). Contents of gadget usage that affect the temperament of preschoolers will cause sleep problems. Nightmares can occur during rapid eye movement (REM) sleep, typically early in the morning, most commonly in preschoolers. Third, increased media use can result in reduced sleep duration through displacement of sleep time (Bathory \& Tomopoulos, 2017). Children who use gadget in evening will increase arousal and behavioral sleep delay and further will cause sleep problems, including increased sleep onset latency, nightmares, frequent night waking and difficulty waking (Garrison et al., 2011).

\section{Education level of the mother}

Based on the OR score, children with mothers who graduated from elementary or junior high or high school had a greater risk of 2.244 experiencing self-care sleep deficits than children with mothers who graduated from college. In the multivariate analysis, the 
mother's education also showed an effect on sleep problems of preschoolers' sleep. This study is in line with the research by (Costa, Barros, \& Santos, 2013), showing that one of the self-care sleep deficits, sleep onset delay in preschoolers was related to mother's education level. Another research also shows that a mother's education was related to the quality of children's sleep (Barazzetta \& Ghislandi, 2017). Girls are usually ensured that when they are adults, they will manage family better and grow children healthier. With education, a woman is also able to educate her children better (Ossai \& Nwalado, 2011). The educated mothers in this study might have a better way to educate their children about sleep hygiene. Thus, their children had less sleep problems compared to the ones with lower educated mothers.

In addition, the results of this study support the research of Bøe, Hysing, Morten, Lundervold, and Sivertsen (2012) which showed that the level of mother's education was related to children's sleep problems, especially bedtime. Healthy sleep patterns can be established and sleep problems could be prevented and managed through sleep-promoting parenting or good sleep hygiene (Bathory \& Tomopoulos, 2017). In neurophysiology of sleep, bedtime routines provide external clues, that sleep is coming and assists children to prepare for sleep mentally by being both predictable and calming. By about 6 months of age, parents should begin using a regular bedtime routine.

\section{Family income}

The result of this study illustrates that family income is related to sleep problems in preschoolers. This result is congruent with a study by Barazzetta and Ghislandi (2017), which concluded that family income influenced children's sleep problems, as well as by Bagley et al. (2016) which showed that socioeconomic status was associated with more subjective complaints at night, more frequent waking at night, fatigue throughout the day and increased sleep disturbance and more pre-sleep worries. Occupation is also related to psychological distress in rural areas (Saifullah et al., 2020).

Families with low incomes will require more effort than high-income families to provide a comfortable home environment for children, including the room environment where children sleep. Home sleeping conditions are associated with poor sleep quality among low-income preschool children. Research found that in their low-income sample, children's poor sleep quality was correlated with the frequency of sharing a room with parents, and with not sleeping alone in their own bed. Co-sleeping was not the only factor associated with poor sleep quality among preschool children involved in the study (Chung et al., 2014).

The results of this study indicate that family and environmental factors are factors related to the occurrence of sleep problems among preschoolers. Family income and mother's education are expected to be factors that can promote a comfortable and safe sleeping environment for children. Mother's education can support the implementation of good sleep hygiene for children by not sharing a bed with children and limiting the use of gadgets before going to sleep.

The current study has some limitations. First, research time was limited, therefore exploration of children's and parents' experiences on bed-sharing could not be done. 
Second, measures of sleep problem were based on parents' reports in which they had to recall the past events. This might result in misclassification.

\section{CONCLUSION}

This study showed that bed sharing, gadget use in two hours before sleep, the education level of the mother, and family income were factors related to sleep problems among preschoolers. This study suggests that health workers should increase their knowledge of the family for modifying environmental and family factors and applying good sleep hygiene for children by limiting bed-sharing and the usage of gadgets before going to sleep. A previous study indicated that bed-sharing is a culture in Indonesia. Hence, it is suggested for further research to explore the experiences of children and parents with bedsharing.

\section{ACKNOWLEDGMENT}

We would like to thank the Directorate of Research and Community Service (DRPM) Ministry of Research, Technology and Higher Education of the Republic of Indonesia for financial support of this study.

\section{CONFLICT OF INTEREST}

The authors declare no conflict of interest.

\section{REFERENCES}

Akacem, L. D., Wright, K. P., \& LeBourgeois, M. K. (2018). Sensitivity of the circadian system to evening bright light in preschool-age children. Physiological Reports, 6(5), 1-10. doi:10.14814/phy2.13617

Amalina, S., Sitaresmi, M. N., \& Gamayanti, I. L. (2015). Hubungan penggunaan media elektronik dan gangguan tidur [Relationship between electronic media use and sleep disorders]. Sari Pediatri, 17(4), 273-278.

Amintehran, E., Ghalehbaghi, B., Asghari, A., Jalilolghadr, S., Ahmadvand, A., \& Foroughi, F. (2013). High prevalence of sleep problems in school- and preschoolaged children in Tehran: A population based study. Iran Journal Pediatr, 23(1), 4552.

Astill, R. G., Heidjen, K. B. V. d, Ijzendoorn, M. H. V, \& Someren, E. J. W. (2012). Sleep, cognition, and behavioral problems in school-age children: A century of research meta-analyzed. Psycological Buletin, 138(6), 1109-1138. doi: 10.1037/a0028204.

Bagley, E. J., Kelly, R. J., Buckhalt, J. A., \& El-sheikh, M. (2016). What keeps low-SES children from sleeping well: The role of presleep worries and sleep environment. Sleep Medicine, 16(4), 496-502. doi:10.1016/j.sleep.2014.10.008

Barazzetta, M., \& Ghislandi, S. (2017). Family income and material deprivation: Do they matter for sleep quality and quantity in early life ? Evidence from a longitudinal study. SLEEP, 40(3), 1-9. doi: 10.1093/sleep/zsw066.

Bathory, E., \& Tomopoulos, S. (2017). Sleep regulation, physiology and development, sleep duration and patterns, and sleep hygiene in infants, toddlers, and preschoolage children. Current Problems in Pediatric and Adolescent Health Care, 47(2), 2942. doi:10.1016/j.cppeds.2016.12.001 
Biggs, S. N., Walter, L. M., Jackman, A. R., Nisbet, L. C., Weichard, J., Hollis, S. L., ... \& Horne, R. S. C. (2015). Long-term cognitive and behavioral outcomes following resolution of sleep disordered breathing in preschool children. Plos One, 10(9), e0139142. doi:10.1371/journal.pone.0139142

Bordeleau, S., Bernier, A., \& Carrier, J. (2012). Longitudinal associations between the quality of parent-child interactions and children's sleep at preschool age. Journal of Family Psychology, 26(2), 254-262. doi:10.1037/a0027366

Bøe, T., Hysing, M., Morten, K., Lundervold, A. J., \& Sivertsen, B. (2012). Sleep problems as a mediator of the association between parental education levels, perceived family economy and poor mental health in children. Journal of Psychosomatic Research, 73(6), 430-436. doi:10.1016/j.jpsychores.2012.09.008

Cheung, C. H. M., Bedford, R., Saez De Urabain, I. R., Karmiloff-Smith, A., \& Smith, T. J. (2017). Daily touchscreen use in infants and toddlers is associated with reduced sleep and delayed sleep onset. Scientific Reports, 7(April), 1-7. doi:10.1038/srep46104

Chung, S., Wilson, K. E., Miller, A. L., Johnson, D., Lumeng, J. C., \& Chervin, R. D. (2014). Home sleeping conditions and sleep quality in low-income preschool children. The Korean Society of Sleep Medicine, 5(1), 29-32. doi: 10.17241/smr.2014.5.1.29

Costa, A., Barros, H., \& Santos, A. (2013). Sleep onset delay and night awakenings in preschool children: The generation XXI birth cohort. Sleep Medicine, 14(13), e41. doi:10.1016/j.sleep.2013.11.061

Dharma, K. K. (2011). Metodologi Penelitian Keperawatan [Nursing research Methodology]. Jakarta: Trans Info Media.

Garrison, M. M., Liekweg, K., \& Christakis, D. A. (2011). Media use and child sleep: The impact of content, timing, and environment. Pediatrics, 128(1), 29-35. doi:10.1542/peds.2010-3304

Hartini, S., Sunartini, Herini, S. E., \& Takada, S. (2017). Item analysis and internal consistency of children's sleep habit questionnaire (CSHQ) in Indonesia version. Belitung Nursing Journal, 3(6), 645-655. I. doi: https://doi.org/10.33546/bnj.184

Hollan, D. (2013). Sleeping, dreaming, and health in rural Indonesia and the urban U.S.: A cultural and experiential approach. Social Science and Medicine, 79(1), 23-30. doi:10.1016/j.socscimed.2012.05.006

Kliegman, R. M., Stanton, B. F., \& St Geme, J. W. (2016). Nelson textbook of pediatrics. Philadelpia: Elsevier.

Li, S., Zhu, S., Jin, X., Yan, C., Wu, S., Jiang, F., \& Shen, X. (2010). Risk factors associated with short sleep duration among Chinese. Sleep Medicine, 11(9), 907916. doi:10.1016/j.sleep.2010.03.018

Lo, M. J. (2016). Relationship between sleep habits and nighttime sleep among healthy preschool children in Taiwan. Annals Academy of Medicine, 140, 40306.

Maanen, A. Van, Roest, B., Moen, M., Oort, F., Vergouwen, P., Paul, I., ... \& Smits, M. (2015). Extreme violation of sleep hygiene: Sleeping against the biological clock during a multiday relay event. Asian Journal of Sports Medicine, 6(4), 1-4. doi:10.5812/asjsm. 25678

Mileva-Seitz, V.R., Bakermans-Kranenburg, M.J., Battaini, C., \& Luijk, M. P.C.M. (2017). Parent-child bed-sharing: The good, the bad, and the burden of evidence. Sleep Medicine reviews, 32, 4-27. doi:10.1016/j.smrv.2016.03.003 
Mindell, J. A., Sadeh, A., Kwon, R., \& Goh, D. Y. T. (2013). Cross-cultural differences in the sleep of preschool children. Sleep Medicine, 14(12), 1283-1289. doi:10.1016/j.sleep.2013.09.002

Ossai, A. G., \& Nwalado, E. N. (2011). Gender and the education of the girl-child in Nigeria. Journal of Qualitative Education, 7(1), 1-7.

Owens, J. A., Spirito, A., \& McGuinn, M. (2000). The Children's Sleep Habits Questionnaire (CSHQ): Psychometric properties of a survey instrument for schoolaged children. Sleep, 23(8), 1043-1051. doi:10.1111/j.1469-8749.2001.tb00204.x

Saifullah, A. D, Latifah, N., Artanti, E. R., Cahyani, K. D., Rahayu, U., Paramarta, L., ... \& Warsini, S. (2020). Mental distress in rural area of Indonesia. Nurse Media Journal of Nursing, 10(1), 1-10. doi:10.14710/nmjn.v10i1.23244

Speirs, K. E., Liechty, J. M., Wu, C. F., Harrison, K., Bost, K., McBride, B., ... \& Fiese, B. (2014). Sleep, but not other daily routines, mediates the association between maternal employment and BMI for preschool children. Sleep Medicine, 15(12), 1590-1593. doi:10.1016/j.sleep.2014.08.006

Tso, W., Rao, N., Jiang, F., Li, A. M., Lee, S., Ho, F. K., .. \& Ip, P. (2016). Sleep duration and school readiness of Chinese preschool children. The Journal of Pediatrics, 169(743413), 266-271. doi:10.1016/j.jpeds.2015.10.064

Wahyuningrum, E., Rahmat, I., \& Hartini, S. (2018). Effect of health education of sleep hygiene on sleep problems in preschoolers. Belitung Nursing Journal, 4(1), 68-75.

Wang, G., Xu, G., Liu, Z., Lu, N., Ma, R., \& Zhang, E. (2013). Sleep patterns and sleep disturbances among Chinese school-aged children: Prevalence and associated factors. Sleep Medicine, 14(1), 45-52. doi:10.1016/j.sleep.2012.09.022

Zahara, D.S., Hartanto, F., \& Adyaksa, G. (2013). Hubungan antara gangguan tidur dengan pertumbuhan pada anak usia 3-6 tahun di Kota Semarang [The correlation between sleep disorders and growth in children aged 3-6 years in Semarang City]. Jurnal Kedokteran Diponegoro, 2(1), 1-16. 